\title{
Usefulness of Robson classification system to analyze caesarean section deliveries: a hospital
}

\author{
based study \\ Tshering Tamang ${ }^{1}$, Jigme Dema ${ }^{2}$, Phuntsho Choden ${ }^{3}$, Sonam Pelden ${ }^{4}$ \\ ${ }^{1-4}$ Department of Obstetrics and Gynaecology, Eastern Regional Referral Hospital, Mongar, Bhutan
}

\begin{abstract}
Introduction: World Health Organization recommends using the Ten-group Robson classification as a standard for assessing and reducing caesarean section (CS) rates. Our study aimed at analyzing CS deliveries using this system with the primary objective of examining the driving factors of increased risk for caesarean delivery. Methods: A retrospective observational study was conducted in Mongar Regional Referral Hospital from $1^{\text {st }}$ January 2016 to $31^{\text {st }}$ December, 2018 recruiting all institutional deliveries and classifying each of them into 10 groups of Robson classification system based on six obstetric variables. Results: There were 2337 deliveries, of which 804 were CS, contributing to a rate of $34.4 \%$. More than three fourth (78.9\%) of caesarean deliveries occurred in Groups 5, 4, 2 and 1. Previous CS was the highest contributor of CS rate and the most common indication. Conclusions: Higher CS rate has been observed in our referral hospital, contributed largely by women with previous CS, induced labour and pre-labour CS. There is a need for implementation of Robson classification system in all tertiary hospitals.
\end{abstract}

Keywords: Caesarean section deliveries; CS rates; Robson classification system.

\section{INTRODUCTION}

Caesarean section (CS) is the most common procedure performed worldwide. The dramatic increase in the rate of this procedure in low, middle and high income countries has become a global concern in recent decades ${ }^{1}$. The average global CS rate is estimated at $18.6 \%$ with the highest being noted in Brazil at $55.6 \%$ followed by the South American sub-region at $42.9 \%{ }^{1}$. WHO had considered the rates to be kept between $10 \%$ and $15 \%$ ,but in 2015, recommended not to focus on achieving a specific rate, and rather focus on making every effort to provide CS to women who really needed $\mathrm{it}^{2}$. Studies have found that there is no additional benefit of non-medically indicated CS in improving maternal and neonatal outcomes ${ }^{3}$.

Caesarean section is of immense benefit to both mother and baby for clinically indicated reasons. However, there are potential short and long-term risks. There is higher risk of maternal morbidity and mortality due to the surgical procedure such as postpartum haemorrhage, increased need for blood transfusion, postpartum infection, longer hospital stay and increased cost; and subsequent pregnancies with placenta previa and accrete syndromes ${ }^{4,5}$.

\section{Corresponding author:}

Tshering Tamang

ttamang@mrrh.gov.bt
Multiple factors have been cited for increasing CS rate, most commonly due to medically un-indicated reasons such as gaining financial compensation, lack of regulatory mechanisms, non-adherence to standard guidelines and fear of litigation. Clinician's personal preferences, perception associated with risks of vaginal birth and CS being a safe and convenient option are also possible reasons ${ }^{6,7}$. Increasing maternal age, obesity and a woman's personal choice and preference for CS are some other factors $^{8,9}$.

WHO in its statement in 2015, proposed the Robson classification system as a global standard for assessing, monitoring and comparing CS rates within healthcare facilities over time, and between facilities ${ }^{2}$. This system is easy to use and classifies all delivering women into 10 groups according to six obstetrical characteristics that are routinely documented and easy to implement. These include (a) gestational age (b) parity (c) number of fetuses (d) fetal presentation (d) mode of onset of labour, and (e) previous $\mathrm{CS}^{10}$. This system has allowed examination and investigation of group specific rate and its contribution to the increasing CS rates; thereby providing evidence to apply appropriate preventive measures to reduce the CS rate and quality improvement ${ }^{11}$.

In Bhutan, medical healthcare services are provided free to all, including all caesarean section. Mongar Hospital is one of the three referral hospitals in Bhutan. It functions as a regional referral hospital for the eight eastern 
districts and manages all complicated pregnancies. CS facilities and level 2 neonatal-care are provided by a trained obstetrician and pediatrician. Due to lack of a formal study and validated data on caesarean deliveries in Bhutan, the factors related to its trends are unknown. As WHO strongly recommends to use Robson classification system, we analyzed our caesarean deliveries according to the prescribed ten groups, with the objective of identifying and examining the driving factors of caesarean delivery.

\section{METHODS}

A retrospective observational study was conducted in the maternity ward of Mongar Regional Referral Hospital from $1^{\text {st }}$ January, 2016 to $31^{\text {st }}$ December, 2018. Prior ethical and administrative clearance had been obtained from Research Ethic Board of Heath, Ministry of Health vide approval letter No. REBH/Approval/2019/018. Women who had hospital deliveries, irrespective of the mode of delivery, was analyzed. However, those who gave birth at less than 22 weeks of gestational age and those whose newborns weighed less than 500 grams at birth were excluded. The birth register maintained in the maternity ward provided patients basic obstetric variables such as maternal age, gravida, parity, gestational age at delivery, mode of delivery and birth weight. The case-files in the Department of Medical Records were referred to for in-depth information on fetal lie prior to delivery, past obstetric history, spontaneous or induced labour and indication for CS.

The six obstetrical characteristics of Robson classification was then used to stratify women into ten groups (Table 1). Each of the groups when defined carefully is totally inclusive but mutually exclusive. Definitions and tools were developed as represented in the WHO implement manual. Data was entered in Microsoft Excel and analyzed using Epidata analysis, poportion and percentages were calculated. A brief analysis of CS indications and its trends over a three year period is discussed. Thorough interpretation of each of the tengroup sizes, their proportionate contribution to CS and possible explanations were attempted to reach out to the most vulnerable group of increased risk of CS deliveries.

\section{RESULTS}

There were 2337 institutional deliveries during the three-year period. Caesarean section constituted 804 deliveries which translated to a rate of $34.4 \%$. Primary CS contributed to $69.6 \%$ of overall CS deliveries. The year-wise trend of CS rate has remained stable at $33.2 \%$ to $35 \%$ from 2016 to 2018 . Most deliveries occurred in multiparous women $(65.2 \%)$ and term pregnancies (93.8\%). Table 2 describes the characteristics of women who delivered during the study period.

Figure 1, indicates the most common indication of caesarean section being previous CS $(29.8 \%)$ followed by labour dystocia (14.5\%) and failed induction of labour (9.9\%). Previous CS cases have increased from $29.4 \%$ in 2016 to $31.2 \%$ in 2018. Similarly, the trend of failed induction of labour and oligohydramnios has gone up by $8.9 \%$ and $3.8 \%$ respectively as shown in Figure 2.

\section{Table 1. The Robson Ten Group Classification System}

\begin{tabular}{cll}
\hline Group & Description \\
\hline 1 & Nulliparous, singleton, cephalic, full-term, spontaneous labour \\
2 & & Nulliparous, singleton, cephalic, full-term, induced labour or pre-labour caesarean section \\
& $2 \mathrm{a}$ & Induced labour \\
& $2 \mathrm{~b}$ & Pre-labour CS \\
3 & & Multiparous, singleton, cephalic, full-term, without a previous caesarean section, spontaneous labour \\
4 & Multiparous, singleton, cephalic, full-term, without a previous uterine scar, induced labour or pre-labour caesarean \\
& section & Induced labour \\
& 4 b & Pre-labour CS \\
5 & Multiparous, singleton, cephalic, full-term, with a previous caesarean section \\
6 & Nulliparous, singleton, breech \\
7 & Multiparous, singleton, breech including previous CS \\
8 & Multiple pregnancy (twins or higher-order multiples) including previous CS \\
9 & Singleton, transverse or oblique lie \\
10 & Singleton, cephalic, preterm including previous CS \\
\hline
\end{tabular}


Table 2. Characteristics of women who delivered in Mongar hospital from 2016-2018 $(n=2337)$

\begin{tabular}{cc}
\hline Characteristics & $\begin{array}{c}\text { All deliveries } \\
\boldsymbol{n}(\mathbf{\%})\end{array}$ \\
\hline Age groups(Years) & \\
$\bullet \quad<20$ & $165(7.1)$ \\
$\bullet \quad 20-29$ & $1388(59.4)$ \\
$\bullet \quad 30-39$ & $703(30.1)$ \\
$\bullet \quad 40$ & $81(3.4)$ \\
Parity & \\
0 & $814(34.8)$ \\
$1-3$ & $1329(56.9)$ \\
$4-6$ & $164(7.0)$ \\
$\geq 7$ & $30(1.3)$ \\
Gestational age at delivery & $143(6.2)$ \\
Preterm & $2194(93.8)$ \\
Term & \\
\hline
\end{tabular}

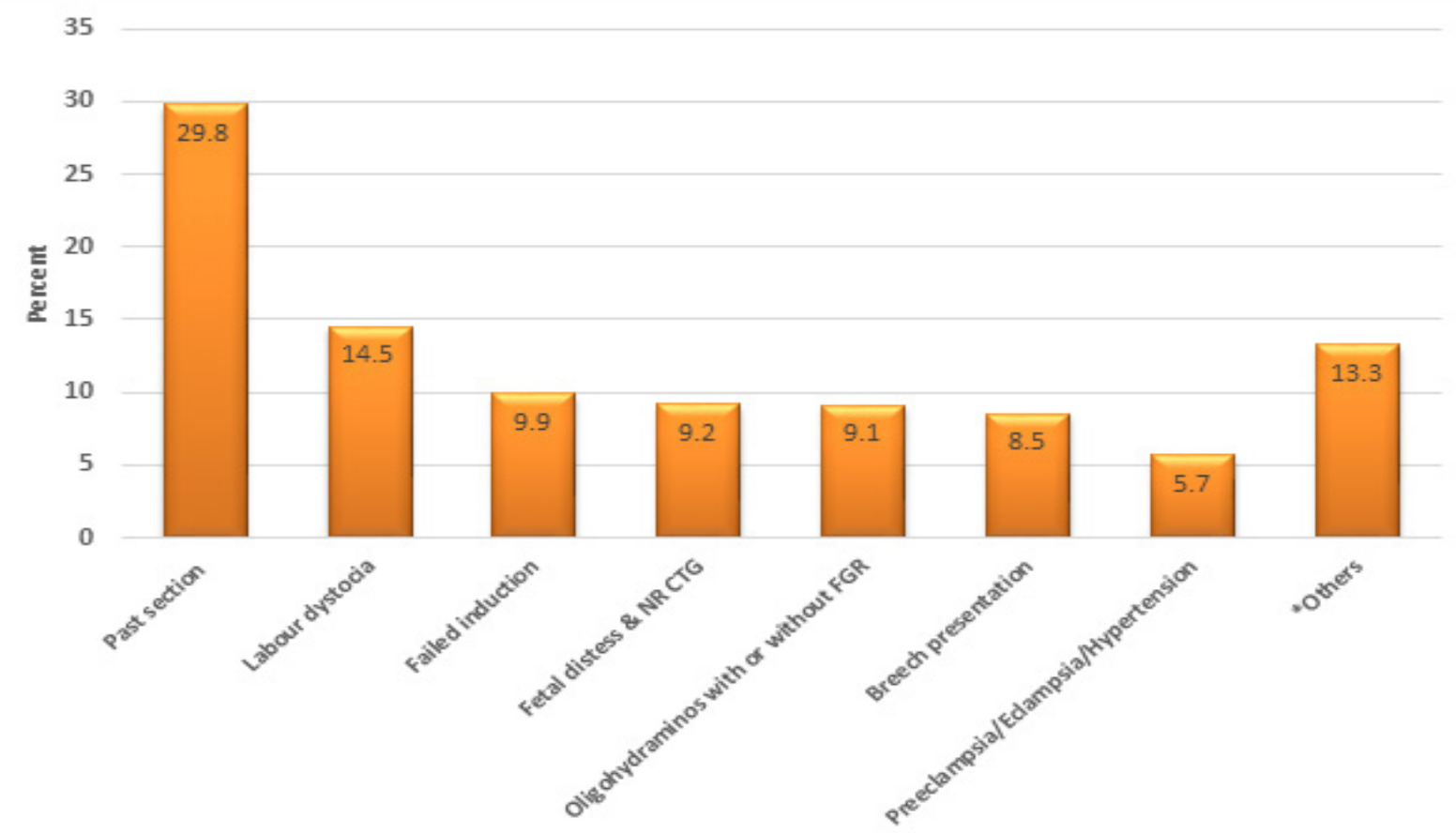

Figure 1. Indications of caesarean sections in Mongar referral hospital from 2016-2018

Note: NR CTG: Non-reassuring CTG, FGR-Fetal Growth Restriction; *Others: Precious pregnancy, Large baby, Grand multigravida, Nuchal cord, Cephalo-pelvic disproportion, membrane rupture and Chorioamnionitis, etc 


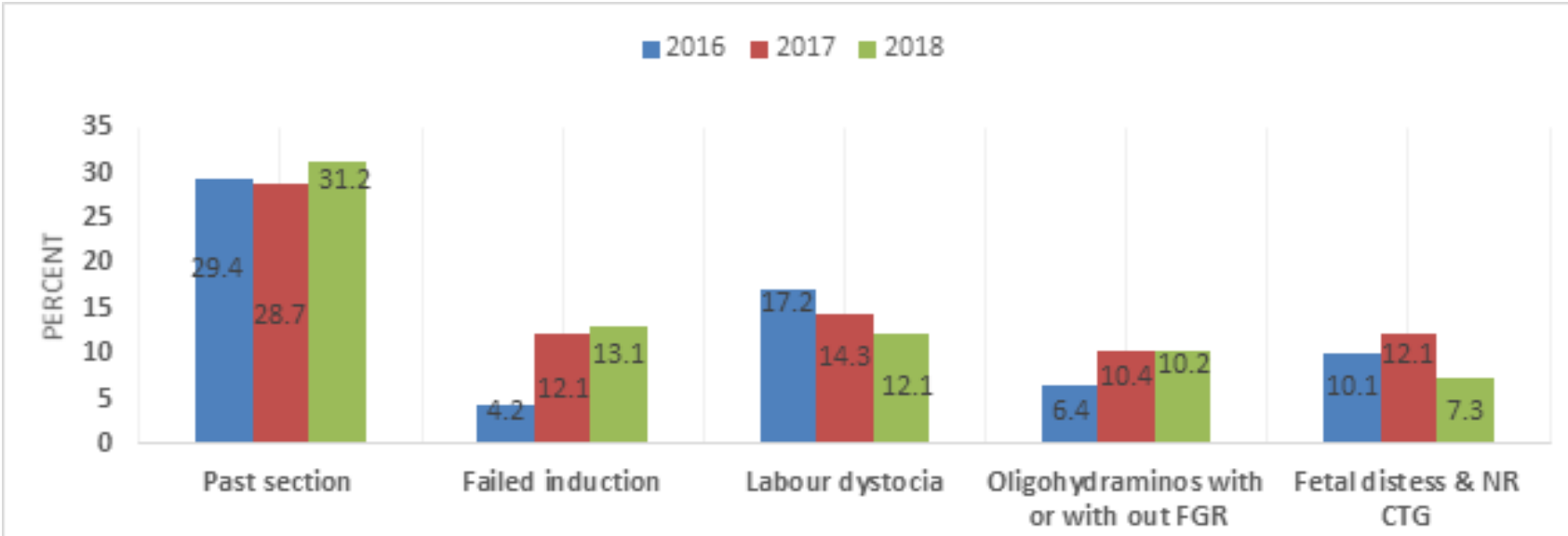

Figure 2. Trend of top 5 indications of caesarean section from 2016-2018 in Mongar RRH

Note: NR CTG: Non-reassuring CTG; FGR-Fetal Growth Restriction

Table 3. Classifying CS deliveries over a 3 year period at Mongar Regional Hospital as per Robson ten-group classification

\begin{tabular}{ccccccc}
\hline Groups & $\begin{array}{c}\text { Number of } \\
\text { women in } \\
\text { group }(\boldsymbol{n})\end{array}$ & $\begin{array}{c}\text { Number of CS } \\
(\boldsymbol{n})\end{array}$ & $\begin{array}{c}* \text { Group Size } \\
(\mathbf{\%})\end{array}$ & $\begin{array}{c}\text { Group CS rate } \\
\mathbf{( \% )}\end{array}$ & $\begin{array}{c}\text { *Absolute group } \\
\text { contribution to } \\
\text { overall CS rate (\%) }\end{array}$ & $\begin{array}{c}\text { ₹elative contribution } \\
\text { of group to overall } \\
\text { CS rate (\%) }\end{array}$ \\
\hline $\mathbf{1}$ & 383 & 81 & 16.4 & 21.1 & 3.5 & 10.1 \\
$\mathbf{2 a}$ & 289 & 80 & 12.3 & 27.7 & 3.4 & 10.0 \\
$\mathbf{2 b}$ & 46 & 46 & 2.0 & 100 & 2.0 & 5.7 \\
$\mathbf{3}$ & 570 & 24 & 24.4 & 4.2 & 1.0 & 3.0 \\
$\mathbf{4 a}$ & 489 & 93 & 20.9 & 19.0 & 4.0 & 11.6 \\
$\mathbf{4 b}$ & 84 & 84 & 3.6 & 100 & 3.6 & 10.4 \\
$\mathbf{5}$ & 231 & 226 & 9.9 & 97.8 & 9.7 & 28.1 \\
$\mathbf{6}$ & 33 & 32 & 1.4 & 97.0 & 1.4 & 4.0 \\
$\mathbf{7}$ & 49 & 43 & 2.1 & 87.7 & 1.8 & 5.3 \\
$\mathbf{8}$ & 24 & 22 & 1.0 & 91.7 & 0.9 & 2.7 \\
$\mathbf{9}$ & 13 & 13 & 0.6 & 100 & 0.5 & 1.6 \\
$\mathbf{1 0}$ & 126 & 60 & 5.4 & 47.6 & 2.6 & $\mathbf{1 0 0 \%}$ \\
\hline
\end{tabular}

*Group size $(\%)=n$ of women in the group / total $N$ women delivered in the hospital $x 100$.

+ Group CS rate (\%) = n of CS in the group / total N of women in the group $x 100$.

$\neq$ Absolute contribution $(\%)=n$ of CS in the group / total N of women delivered in the hospital $x 100$.

§Relative contribution (\%) $=n$ of CS in the group / total N of CS in the hospital $x 100$ 
Table 3 classifies the delivering women as per Robson's group. More than three-fourth of all CS (89.5\%) was contributed to by the groups $1,2,3,4$ and 5 .

The CS rates in Groups 1 (Nullipara, singleton, term, cephalic, spontaneous labour women) and 3 (Multipara, singleton, term, cephalic, spontaneous labour) were $21.1 \%$ and $4.2 \%$ respectively. In both groups, the most common indications were labour dystocia (59 of 81 vs 9 of 24 ) and fetal distress (15 of 81 vs 10 of 24 ).

The CS rate of group 2 (Nullipara, term, cephalic, induced labour or pre-labour CS) was $38.7 \%$ and group 4 (Multipara, term, cephalic, induced labour or pre-labour CS) was $30.7 \%$. Labour was induced in about $33 \%$ in these two groups. Of those induced, $27.7 \%$ of nulliparous (Group 2a) and 19\% of multiparous (Group 4a) had to undergo caesarean delivery. The most frequent reason for induction was postdated pregnancy. The induction success rate was $72.3 \%$ in nullipara and $81 \%$ in multipara. The common indications for CS among nulliparous women were labour dystocia (32 of 80) and failed induction (27 of 80 ), while in multiparous women; it was failed induction (55 of 93). Pre-labour CS occurred in about $15 \%$ in groups 2 and 4. Multipara (4b) had a slightly higher rate of $3.6 \%$ compared to nullipara (2b) at $2.0 \%$. In both groups, the most common indication for pre-labour CS was oligohydramnios with or without fetal growth restriction (35.1\% in nullipara and 50.6\% in multipara).

Group 5 comprised term cephalic pregnancies with a previous CS. This group contributed the highest to the overall CS rate $(9.7 \%)$.

Group 10 comprised of preterm, singleton and cephalic fetuses and this group contributed $2.6 \%$ to the total CS rate. $40 \%$ of this group underwent pre labour CS due to severe hypertensive disorder.

\section{DISCUSSION}

The caesarean rate of $34.4 \%$ of our hospital was above the WHO recommended rate which is comparable to the rate in United States $(32.8 \%)$ and New Zealand $(33.4 \%)^{1}$. Worldwide, the CS rates has increased from $6.7 \%$ in 1990 to $19.1 \%$ in $2014^{1}$. The higher CS rate in our finding could be explained by higher referral of complicated pregnancies to our obstetric centre.

Our result showed that three fourth of CS was contributed to by groups 5, 4, 3,2 and 1, which was similar to a finding from another study ${ }^{12}$. Group 5 (term previous CS) was the major contributor to CS rate $(9.7 \%$ of $34.4 \%)$, similar to the findings of a multi-country survey as well as other study in Canada ${ }^{10,13}$. Most women in this group had undergone elective $\mathrm{CS}$ in their second and subsequent pregnancies owing to lack of 'Vaginal Birth After Caesarean' (VBAC) protocol in our centre. In an appropriately selected patient, vaginal delivery success rate with VBAC is at $72-75 \%$ with low maternal and perinatal morbidity according to Royal College Obstetrician and
Gynaecologist (RCOG) guidelines ${ }^{14}$. Obstetric practices in many European countries offer VBAC to women with previous $\mathrm{CS}^{15}$. In our setting, the difficulty with continuous monitoring of laboring patients who have previous CS, the relative difficulty in access to operation facility and the limited resources poses a significant challenge to the conduct of VBAC. With adequate resources and clear guidelines, on practice of VBAC should be implemented across Bhutan, which could drastic reduction in CS rates.

Similar to the analysis by Vogel, higher proportion of labour induction and pre-labour CS as compared to spontaneously laboring multiparous women were found ${ }^{10}$. Group 4 contributed substantially to CS rate probably due to its large size, frequent labour induction and pre-labour CS in our hospital. This finding suggests that labour induction has higher risk for CS. The recent ARRIVE trial as well as a meta-analysis has not shown any association between induction and a higher CS rate. They reported that an elective induction at 39 weeks has been cost-effective and reduces the rate of $\mathrm{CS}^{16,17}$. The difference in findings could be due to poor patient selection, the choice of inducing agents/methods and poorly and vaguely defined 'failed induction'.

Pre-labour CS in the nullipara and multipara in group $2 \mathrm{~b}$ and $4 \mathrm{~b}$ had substantially added to the overall CS rate. In both groups, the most common indication was oligohydramnios with or without fetal growth restriction (FGR). Elective induction of labour for isolated oligohydramnios is not a contraindication and has favorable outcome without increasing CS rate ${ }^{18}$. The practice of amnio-infusion during labour which prevents cord compression and fetal distress is the constraint in our setting. Other indications of pre-labour CS were grand multigravida, nuchal cord, precious baby, cephalo-pelvic disproportion, membrane rupture and chorioamnionitis; which could have been avoided by induction of labour.

The CS rate among groups 1 and 3 were relatively high. These group of women had normal spontaneous labour, and frequently ended up having CS. Labour abnormality (protracted/ arrest labour) and fetal distress were the most common reasons where substantial number of nulliparas had primary CS. Freidman's description of labour duration and beginning of active stage has been argued and refuted; a recent analysis by Consortium on Safe Labour (CSL) reports labour progression is much slower until $6 \mathrm{~cm}$ of cervical dilatation ${ }^{19}$. WHO in 2018 has come up with firm recommendations on labour; that the active $1^{\text {st }}$ stage will begin from cervical dilatation of $5 \mathrm{~cm}$ and last at least 12 hours duration in primigravida ${ }^{20}$. Using this guideline strictly and intervening only when needed can reduce many abnormal labours and can reduce primary CS in these groups.

Fetal heart rate abnormality and fetal distress are increasingly a cause for emergency CS in laboring patients. Cardiotocography has higher false positivity leading to increasing CS rate from non-reassuring fetal heart pattern and fetal distress ${ }^{21}$.National Institute for Health and Care Excellence (NICE) guidelines agree that fetal scalp blood sampling and blood gas analysis can be an alternative tool to rule out acidosis 
and fetal compromise, preventing up to $90 \%$ of CS and operative interventions ${ }^{22,23}$. In our centre, unavailability of the test and lack of clinical acumen poses difficulty in assessing fetal academia. This may have led to subjective diagnosis of fetal distress, thereby increasing CS rate.

In Groups 6 and 7, breech presentation has contributed $3.2 \%$ to the overall CS rate of $34.4 \%$ which is within the limits of recommendation, as it is a small group. Vaginal breech deliveries are becoming obsolete as more and more patients and clinicians are opting for CS due to fear of complications, especially after the reports of 'Term breech trial' ${ }^{24}$. However, recent evidences and recommendation from the Royal College of Obstetricians and Gynaecologists confirms the minimal risk of external cephalic version (ECV) and vaginal breech delivery (VBD) in adequately selected patients ${ }^{25}$.

Nearly half of the women with preterm deliveries $(47.6 \%)$ in Group 10 had to undergo pre-labour CS particularly due to maternal hypertensive disorder (23 of 60 ). There is arguable dilemma and decision to choose between induction of labour or caesarean section in moderate pre-eclampsia, preterm PROM and oligohydramnios among obstetricians. It has been noted that induction of labour does not increase caesarean section rates $^{16,18}$.

It is evident that some correctable measures are visible in our obstetric practice. A highest degree of understanding and consensus among obstetricians and policy makers is required. First, clinical protocols must be developed regarding the indications of CS based on recent guidelines and current global practices. Second, policy and administrative support on adequacy of resources and facility development must be improved; particularly manpower to monitor laboring patients adequately; labour analgesia and emergency anesthetic facilities. Third, implementation and incorporation of Robson's ten group classification system as a part of audit and quality improvement in tertiary hospitals will curb unnecessary CS rate.

This study is the first of its kind to use Robson classification system to analyze caesarean rate in a referral hospital in Bhutan involving large number of subjects with adequate data.

The limitation of this study pertains to instances where patients were referred out for induction of labour or caesarean section when the obstetrician was out for training, which could have affected the rate determination and analysis of groups in Robson classification.

\section{CONCLUSIONS}

High caesarean section rate has been observed in Mongar Regional Referral Hospital, contributed largely by women with previous CS, induced labour and pre-labour CS. Implementation of Robson classification system in all tertiary hospitals; and development of guidelines with consensus among obstetricians and policy makers is vital to reduce the CS rate without compromising the health of babies and mothers.

\section{REFERENCES}

1. Betrán AP, Ye J, Moller A, Zhang J, Gülmezoglu AM. The increasing trend in caesarean section rates: Global, Regional and National Estimates : 1990-2014. PLoS One. 2016;11(2):e0148343. [Full Text | DOI]

2. World Health Organization; Human Reproduction Programme.WHO statement on caesarean section rates. Reprod Heal Matters. 2015;(23):149-50. [Full Text]

3. Ye J, Zhang J, Mikolajczyk R, Torloni MR, Gülmezoglu AM, Betran AP. Association between rates of caesarean section and maternal and neonatal mortality in the $21^{\text {st }}$ century: a worldwide population-based ecological study with longitudinal data. An Int J Obstet Gynaecol. 2016;123(5):745-53. [Full Text | DOI]

4. Villar J, Carroli G, Zavaleta N, Donner A, Wojdyla D, et al. Maternal and neonatal individual risks and benefits associated with caesarean delivery: multicentre prospective study. Br Med J. 2007;335(7628):1025-9. [Full Text | DOI]

5. Keag OE, Norman JE, Stock SJ. Long-term risks and benefits associated with cesarean delivery for mother, baby and subsequent pregnancies: systematic review and metaanalysis. PLoS One. 2018;56:1-22. [Full Text | DOI]

6. Tadevosyan M, Ghazaryan A, Harutyunyan A, Petrosyan V, Atherly A, Hekimian K. Factors contributing to rapidly increasing rates of cesarean section in Armenia: a partially mixed concurrent quantitative-qualitative equal status study. BMC Pregnancy Childbirth. 2019;19(1):1-10. [Full Text | DOI]

7. Panda S, Begley C, Daly D. Clinicians' views of factors influencing decision-making for caesarean section: a systematic review and metasynthesis of qualitative, quantitative and mixed methods studies. PLoS One. 2018;13(7):1-27. [Full Text | DOI]

8. Bohren MA, Shakibazadeh E, Betran AP, Shirzad M, Abedini M. Women's perspectives on health facility and system levels factors influencing mode of delivery in Tehran: a qualitative study. Reprod Health. 2019;16(1):1-11. [Full Text | DOI]

9. Kirchengast S, Hartmann B. Recent lifestyle parameters are associated with increasing caesarean section rates among singleton term births in Austria. Int J Environ Res Public Health. 2019;16(1):1-13. [Full Text | DOI]

10. Vogel JP, Betrán AP, Vindevoghel N, Souza JP, Torloni MR, Zhang J, et al. Use of the robson classification to assess caesarean section trends in 21 countries: a secondary analysis of two WHO multicountry surveys. Lancet Glob Heal. 2015;3(5):e260-70. [Full Text | DOI] 
11. Boatin AA, Cullinane F, Torloni MR, Betrán AP. Audit and feedback using the Robson classification to reduce caesarean section rates: a systematic review. BJOG An Int J Obstet Gynaecol. 2018;125(1):36-42. [Full Text | DOI]

12. Roberge S, Dubé E, Blouin S, Chaillet N. Reporting caesarean delivery in Quebec using the Robson classification system. J Obstet Gynaecol Canada. 2017;39(3):152-6. [Full Text | DOI]

13. Kelly S, Sprague A, Fell DB, Murphy P, Aelicks N, Guo Y, et al. Examining caesarean section rates in Canada using the Robson classification system. J Obstet Gynaecol Canada. 2013;35(3):206-14. [Full Text | DOI]

14. Royal College of Obstetrician and Gynaecologists. Birth after previous caesarean birth. Green-top Guideline No. 45. Royal College of Obstetrician and Gynaecologists. [Internet]. Accessed on 2020 April 27. [Full Text]

15. Devarajan S, Talaulikar VS, Arulkumaran S. Vaginal birth after caesarean. Obstet Gynaecol Reprod Med. 2018;28(4):110-5. [Full Text | DOI]

16. Carmichael SL, Snowden JM. The ARRIVE Trial: Interpretation from an epidemiologic perspective. J Midwifery Womens Health. 2019;1-7. [Full Text | DOI]

17. Hersh AR, Skeith AE, Sargent JA, Caughey AB. Induction of labor at 39 weeks of gestation versus expectant management for low-risk nulliparous women: a cost-effectiveness analysis. Am J Obstet Gynecol. 2019;220(6):590.e1-590. e10. [Full Text | DOI]

18. Krispin E, Netser T, Wertheimer A, Salman L, Chen R, Wiznitzer A, et al. Induction of labor methods in isolated term oligohydramnios. Arch Gynecol Obstet. 2019;299(3):76571. [Full Text | DOI]
19. Laughon SK, Branch DW, Beaver J, Zhang J. Changes in labor patterns over 50 years. Am J Obstet Gynecol. 2012;206(5):419.e1-419.e9. [Full Text | DOI]

20. World Health Organization. WHO Recommendations: Intrapartum care for a positive childbirth experience. 2018. [Full Text]

21. Alfirevic Z, Gml G, Cuthbert A, Devane D. Continuous cardiotocography ( CTG ) as a form of electronic fetal monitoring ( EFM ) for fetal assessment during labour. Cochrane Database Syst Rev. 2006;19;(3):CD006066. [Full Text | DOI]

22. National Institute for Health and Clinical Excellence. Intrapartum care for healthy women and babies: clinical guideline. 2014. [Internet]. Accessed on 2020 April 7.

23. Hilal Z, Mrkvicka J, Rezniczek GA, Dogan A, Tempfer CB. Accuracy of intrapartum fetal blood gas analysis by scalp sampling: a retrospective cohort study.Medicine (Baltimore). 2017;96(49):e8839. [PubMed | Full Text | DOI]

24. Hannah ME, Hannah WJ, Hewson SA, Hodnett ED, Saigal S, Willan AR, et al. Planned caesarean section versus planned vaginal birth for breech presentation at term: a randomised multicentre trial Mary. Lancet. 2000;356(9239):1375-83. [Full Text $\mid \mathrm{DOI}]$

25. Royal College of Obstetricians and Gyaecologists. Management of breech presentation: Green-top Guideline No. 20b. BJOG An Int J Obstet Gynaecol. 2017;124(7):e15177. [Full Text]

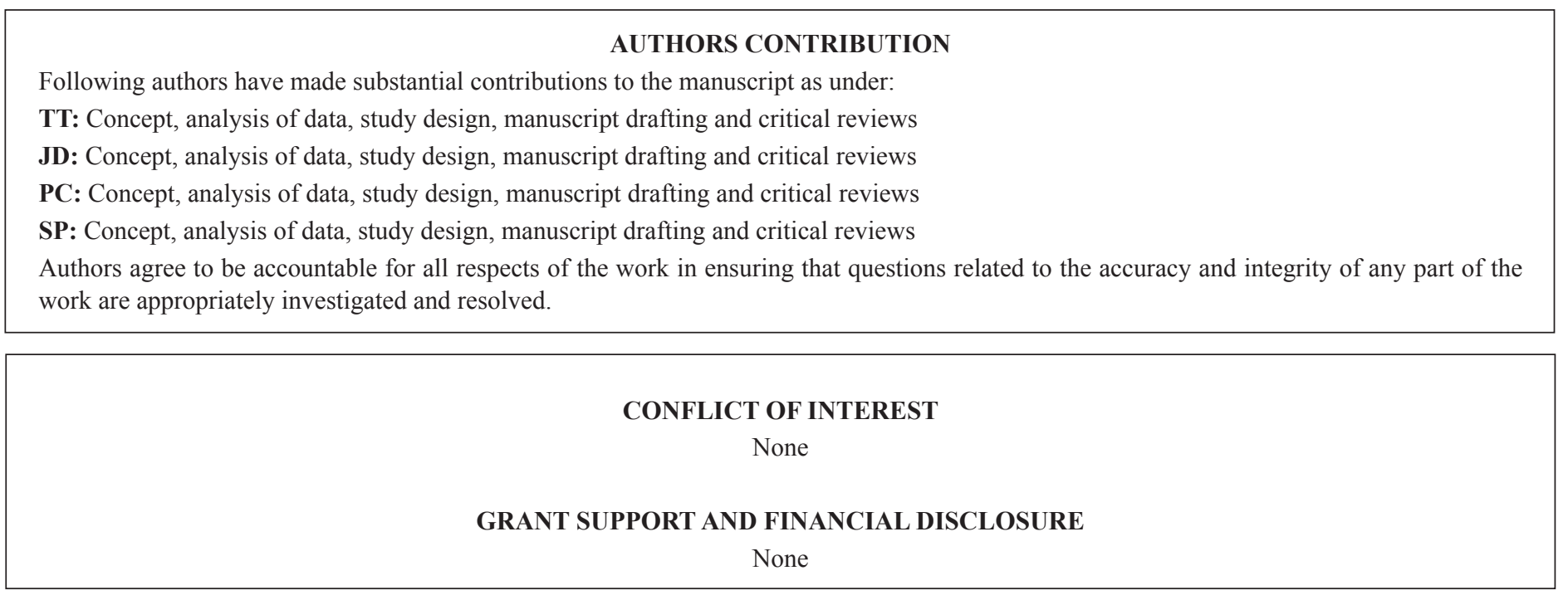

